\title{
VARIATION OF F-CENTER CONCENTRATION IN DILUTE K-KCL SOLUTION: COMPARISON OF AN OPTICAL STUDY WITH THERMODYNAMIC PREDICTION
}

\author{
Th. RAUCH, D. NATTLAND and W. FREYLAND \\ Institute of Physical Chemistry, University Karlsruhe, Kaiserstrasse 12, D-7500 Karlsruhe, Germany
}

\begin{abstract}
We have measured the concentration of liquid F-centers by optical absorption in $\mathrm{K}_{\mathbf{X}} \mathrm{KCl}_{1-\mathbf{X}}$ solutions at $790{ }^{\circ} \mathrm{C}$ over a wide range of compositions up to a metal mole fraction $x=0.01$. The composition has been accurately controlled by coulometric titration in situ. These results are compared with the predicitions of the F-center concentration as determined from metal activity measurements using a thermodynamic electron defect model. Good agreement is found between these separate data sets for a variation of composition by two orders of magnitude.
\end{abstract}

\section{Introduction}

The F-center (colour center) is the first and best studied electronic defect species in solid state physics and chemistry. It is described as an electron localized at an anion vacancy /1/. Spectroscopically the crystalline F-center has been characterized in detail by various methods during more than six decades, going back to the pioneering work of Pohl's school in Göttingen - for reviews see $/ 2 /, / 3 /-$. However, its thermodynamic properties like chemical potential or reaction enthalpy for the equilibrium F-center - colloid and the correlation between thermodynamic and electronic properties are less well studied. This is mainly due to the fact that the phase width of the metal doped alkali halides is very narrow and thus allows only a small equilibrium concentration of F-centers of e.g. $10^{18} \mathrm{~cm}^{-3}$ at $600{ }^{\circ} \mathrm{C} / 4 /$. In addition, crystalline $\mathrm{F}$-centers in most cases have been produced by additive colouration through the vapour phase and the colloids have been formed by quenching, a non equilibrium state. Markham $/ 3 /$, p. 62 , admires this as "an art and not a science". As a matter of fact, a variety of electronic defect equilibria has been considered in solid state chemistry - see e.g. Kröger $/ 5 /$ - . But in many cases the experimental verification in solids is limited to a relatively narrow concentration or activity range due to the phase behaviour or experimental difficulties at the necessary high temperatures. 
In alkali metal - alkali halide melts the situation is different. Here a complete miscibility in thermal equilibrium exists at elevated temperatures of the order of $10^{3} \mathrm{~K} / 6 /$. Spectroscopic and theoretical studies strongly indicate that on the salt-rich side of these solutions F-center like states form - for a recent review see /7/. Deviations from this may be considered for $\mathrm{M}-\mathrm{NaX}$ and $\mathrm{M}-\mathrm{LiX}$ systems $/ 8 /, / 9 /$. In connection with the considerations on electronic defect models above these systems offer the particular attraction that the corresponding thermodynamic equilibria can be followed over a wide range of composition and corresponding thermodynamic metal activities where clearly non ideal behaviour prevails.

In this study emphasis is given to this point. The concentration of F-centers in liquid $\mathrm{K}_{\mathrm{X}} \mathrm{KCl}_{1-\mathrm{X}}$ has been determined optically for a variation of metal mole fraction $\mathrm{x}$, $10^{-4} \leq x \leq 10^{-2}$, where $x$ has been varied in situ by coulometric titration. These data are compared with the corresponding predictions of an electron defect model which uses as input data measured metal activities $/ 10 /, 11 /$.

\section{Experimental}

In order to control and vary in situ the composition of the $\mathrm{K}_{\mathrm{X}} \mathrm{KCl}_{1-\mathrm{x}}$ melt accurately, we have combined an EMF-cell with the optical cell as sketched in Fig. 1. The EMF-cell allows coulometric titration of the $\mathrm{K}$-metal according to the following reaction:

$$
\mathrm{Ca}, \mathrm{Sn}(\mathrm{l})\left|\mathrm{CaF}_{2}(\mathrm{~s})\right| \mathrm{K}, \mathrm{KCaF}_{3}(\mathrm{~s})-\mathrm{K}, \mathrm{KCl}(1)
$$

This technique using $\mathrm{CaF}_{2}$ as a solid electrolyte was first employed by Egan on liquid alloy studies $/ 12 \%$. Details of the operation of this method and the necessary corrections to determine the metal amount dissolved in the molten salt are also described in two previous papers where it has been applied to metal molten salt solutions /13/,/14/.

For the following only the principle of titration with this EMF-cell is of interest: for a given EMF the $\mathrm{K}$-metal activity in the double salt $\mathrm{KCaF}_{3}$ is fixed, and via equilibration through the vapour phase the same activity is present in the molten salt. For further details reference is given to $/ 13 /, / 14 /$. The optical part of the cell in principle consists of two cir cular sapphire windows sealed vacuum tight with a thin Ta- or Fe-wire defining the thickness of the liquid salt film of about $20 \mu \mathrm{m}$. Further details of the optical cell and measurements are described in $/ 15 \%$. Two comments on this experiment are of importance. On titration of the metal, equilibration in the optical film is fast, of the order of minutes. However, so far we did not succeed to keep the concentration constant over a long period of several hours. This is easily detected by the optical exctinction and changing EMF. There are either electronic leakage currents which discharge the cell slowly - due, e.g., to impurity deposition on $\mathrm{CaF}_{2}$ or reactions at high temperatures - or the cell is not absolutely tight. So in 
the present experiments we were not yet able to count the charge reliably enough to determine directly the amount of metal dissolved; but we set a constant potential $\mathrm{E}$ when taking the spectra which defines the metal activity $a_{k}$ via the Nernst equation. Through these activities the mole fractions $\mathrm{x}$ have been determined from the thermodynamic measurements of $a_{k}(x) / 11 /$.

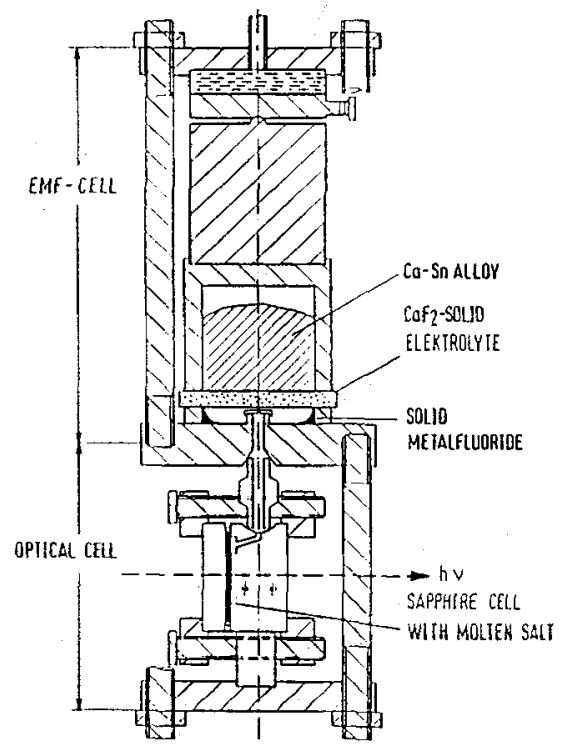

Fig. 1: High temperature optical absorption cell combined with an EMF-cell for in situ coulometric titration.

\section{Results and Discussion}

Typical absorption bands of the F-center in liquid $\mathrm{K}_{\mathrm{X}} \mathrm{KCl}_{1-\mathrm{x}}$ at $790{ }^{\circ} \mathrm{C}$ are presented in Fig. 2 for various EMF-values ranging from $150 \mathrm{mV}$ to $-10 \mathrm{mV}$. The spectra shown have been corrected for the absorption background measured on the pure molten salt before titration. An uncertainty in the background may be due to slight corrosion of the sapphire windows. This has been checked and corrected by measurements on the pure salt after taking out the metal by titration. The temperature has been calibrated relative to the melting point of the pure salt by observation of the fundamental absorption edge of the salt. The absolute accuracy is found to be $\pm 5{ }^{\circ} \mathrm{C}$. The spectra have been reproduced at various titrations in the same run and with separate fillings in different experiments to better than 0.1 extinction units at the same EMF. 


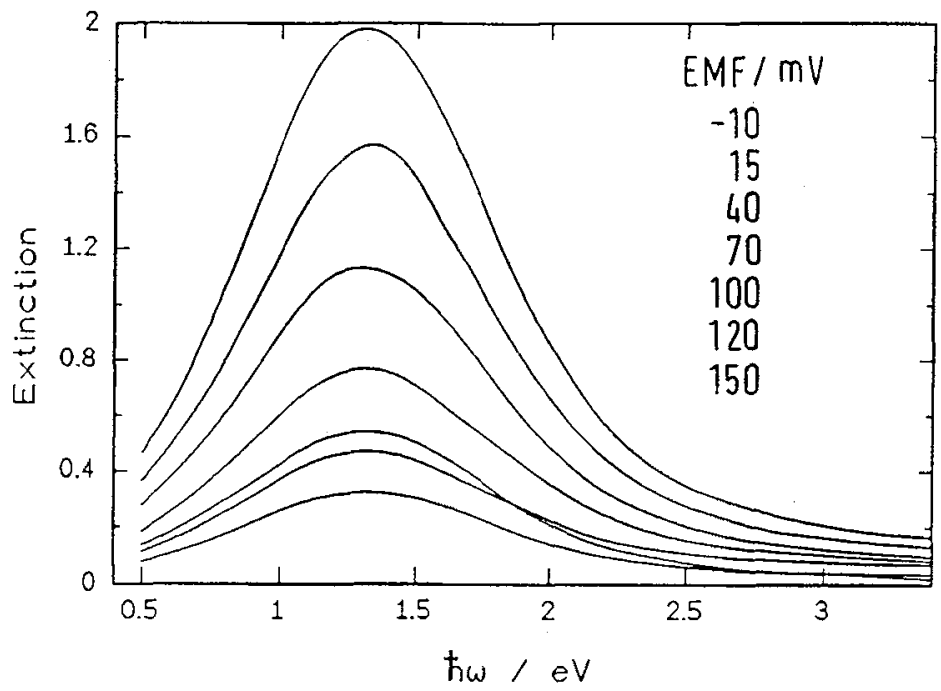

Fig. 2: Selection of optical absorption spectra of $\mathrm{K}_{\mathrm{X}} \mathrm{KCl}_{1-\mathrm{X}}$ at $790{ }^{\circ} \mathrm{C}$ for various titrations with increasing and decreasing EMF and corresponding $x$-values $0.0007 \leq x \leq 0.0034$. Plotted is the extinction vs photon energy in eV. Increasing EMF-values correspond to decreasing extinctions.

In Fig. 2 it is apparent that the width of the absorption band at half maximum does not change with composition. So the height of the band, or the absorption constant at the band maximum, $\mathbf{K}$, is directly proportional to the concentration of F-centers, $\mathbf{n}_{\mathbf{f}}$. The $\mathrm{K}$-values have been determined with Beer's law from the extictions. The film thickness has been determined after the experiment by measuring the thickness of the sealing wire with a light section microscope. These data of $\mathrm{K} / \mathrm{cm}^{-1}$ are plotted in Fig. 3 as a function of $\mathrm{K}$-activity, $a_{K}$. Here the $a_{K}$-values have been determined from the experimental EMF via the Nernstequation, i.e.

$$
a_{K}=\exp \left(-\frac{\left(E-E_{0}\right) F}{R T}\right)
$$

where $F$ is the Faraday constant, $R$ is the gas constant, and $E_{O}$ is the EMF at saturation of the double salt - see /13/-. As can be seen in Fig. 3 the reproducibility of data from different experiments - circles in comparison with triangles - is very good. 


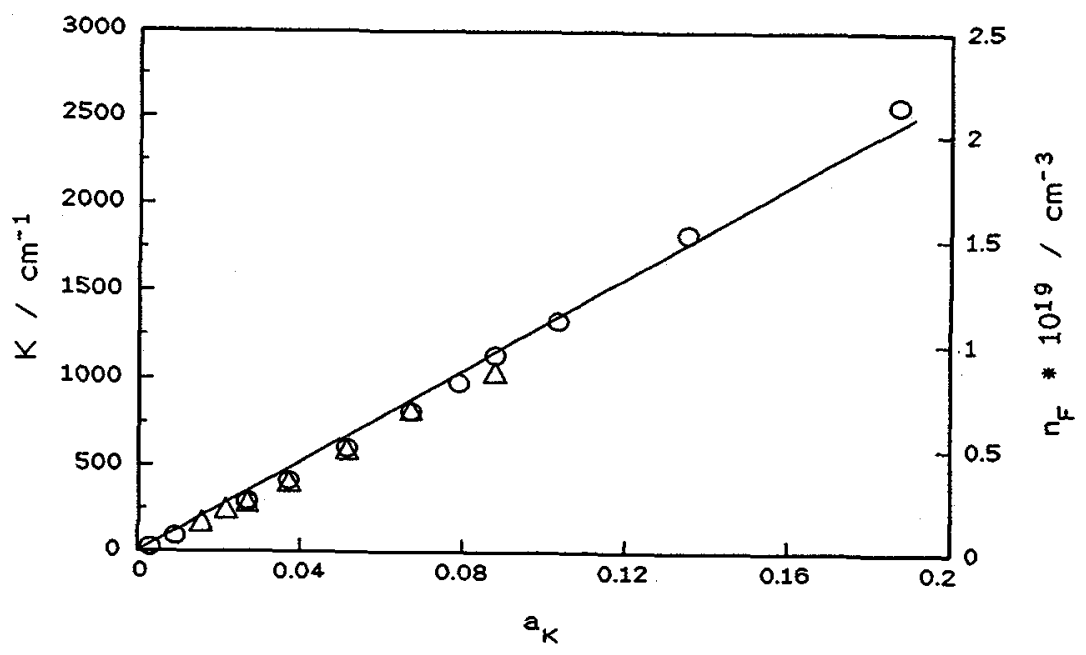

Fig. 3: Absorption constant, $K$, at the band maximum as a function of $K$-metal activity, $a_{K}$, of $\mathrm{K}_{\mathrm{x}} \mathrm{KCl}_{1-\mathrm{x}}$ at $790{ }^{\circ} \mathrm{C}$. Comparison of results from different optical experiments (symbols $O$ and $\Delta$ ) with the prediction of thermodynamic defect model (full line).

The concentration $n_{F}$ of $F$-centers (right hand scale) has been determined from the spectra via the corresponding $\mathrm{K}$-values using the Smakula equation - see e.g. /3/ -. For the $n_{F^{-}}$data from thermodynamics see text.

However, the most interesting observation is that the concentration of F-centers (proportional to $\mathrm{K} / \mathrm{cm}^{-1}$ ) over almost two orders of $a_{K}$ follows a straight line. This exactly is the prediction of the thermodynamic defect model, which is described in detail in $/ 12 /$ and $/ 13 /$. It considers with increasing metal concentration the formation of electrons - which may be spread in localized states in the mobility gap -, F-centers, and higher aggregated states. Taking into account the corresponding equilibria which define the equilibrium constants $K_{i}$ one finds $/ 13 /$ :

$$
{ }_{\mathrm{F}}=\left(\mathrm{K}_{\mathrm{VII}}^{-1} / \mathrm{a}_{\mathrm{K}}^{\mathrm{I}}\right) \cdot \mathbf{a}_{\mathrm{K}} \cdot\left(\mathrm{N}_{\mathbf{A}} / \mathrm{v}_{\mathbf{m}}\right)
$$

where $\mathrm{K}_{\text {VII }}^{-1}$ is the equilibrium constant for the ionisation of the F-center and the constant $a_{k}^{I}$ is the activity where the concentrations of electrons and F-centers are equal, $N_{A}$ is the Avogadro constant and $V_{m}$ the molar volume. The constant $K_{V I I}^{-1}$ and $a_{K}^{I}$ have been determined 
from fitting the model equations to measured activities /11/ and measured electronic conductivities $/ 16 /$. So these constants define the slope of $n_{F} v s a_{K}$, which is presented by the straight line in Fig. 3. If one plots $K$ or $n_{F}$ versus $x$ clear deviations from a linear behaviour are observed, as is demonstrated in Fig. 4. This is not surprising as ideal behaviour does not hold any more at these high activities. In the solid, where the maximum F-center concentration in thermal equilibrium is much lower, a linear relation between $n_{F}$ and $x_{K}$ over three orders of magnitude has been found - see e.g. /4/ -.

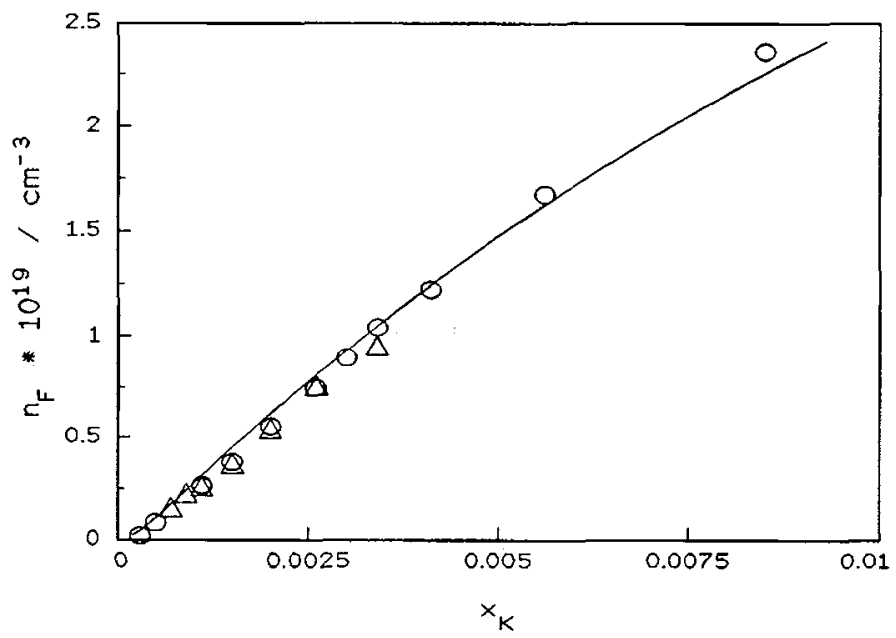

Fig. 4: Concentration of $F$-centers, $\mathrm{n}_{\mathrm{F}}$, versus mole fraction $\mathrm{x}$ of liquid $\mathrm{K}_{\mathrm{X}} \mathrm{KCl}_{1-\mathrm{X}}$ at $790{ }^{\circ} \mathrm{C}$. Symbols correspond to optical determination, full line to thermodynamic model. For the determination of $n_{F}$ via the Smakula equation /3/ the oscillator strength is taken as 1 .

In summary we may conclude that the optically determined concentration dependence of F-centers presented here for $\mathrm{K}_{\mathrm{X}} \mathrm{KCl}_{1-\mathrm{X}}$ melts quantitatively agrees with the predictions of a thermodynamic electronic defect model based on measured activities. The agreement comprises both the linear dependence of $n_{F}$ vs $a_{K}$ and the slope.

\section{Acknowledgement:}

We thank Dr. J.J. Egan for his valuable contribution in the critical evaluation and analysis of the thermodynamic measurements. Financial support of this work by the Deutsche Forschungsgemeinschaft and the Fonds der Chemischen Industrie is gratefully acknowledged. 


\section{References}

(1) Kittel, Ch., Einführung in die Festkörperphysik 1988 (Oldenbourg Verlag, München)

(2) Fowler, W.B., Physics of Colour Centers, 1968 (Academic Press, New York)

(3) Markham, J.J., F-Centers in Alkali Halides, 1966 (Academic Press, New York)

(4) Rögener, R., Ann. Physik 29 (1937) 386

(5) Kröger, I.A.; The Chemistry of Imperfect Crystals, 2nd edition, 1974 (North Holland, Amsterdam)

(6) Bredig, M., in: Molten Salt Chemistry, ed. M. Blander, 1964 (Interscience, New York)

(7) Warren, W.W. Jr., in: The Metallic and Nonmetallic states of Matter, eds. P.P. Edwards and C.N.R. Rao, 1985 (Taylor and Francis, London)

(8) Xu, L.F., Selloni, A., and Parrinello, M., Chem. Phys. Lett. 162 (1989) 27

(9) Schindelbeck, Th., Nattland, D., and Freyland, W., these Proceedings, 1991

(10) Smirnov, M.V., Chebykin, V.V. and Tsivokina, L.A., Electrochem. Acta 26 (1981) 1275

(11) Schummer, J., Schulz, T., Bernard, J., Heyer, H., and Freyland, W., 1991, to be published.

(12) Egan, J.J., High Temperature Science, 19 (1985) 111

(13) Egan, J.J., and Freyland, W., Ber.Bunsenges. Phys. Chem. 89 (1985) 381

(14) Haarberg, G.M., Osen, K.S., Egan, J.J., Heyer, H., and Freyland, W., Ber. Bunsenges. Phys. Chem. 92 (1988) 139

(15) Freyland, W., Garbade, K., Heyer, H., and Pfeiffer, E., J.Phys.Chem. 88 (1984) 3745

(16) Egan, J.J., private communication. 